\title{
Sustainable utilisation of Eppawala Rock Phosphate mediated by Phosphate Solubilizing Microbes: A timely action
}

\author{
Ranasinghe R.K.R.S.*, Naayakkara C.M. \\ Department of Plant Science, University of Colombo, Sri Lanka \\ *rajika.ranasinghe@gmail.com
}

\begin{abstract}
Eppawala Rock Phosphate (ERP) reservoir is the major phosphate mineral resource in Sri Lanka which is recommended only for perennial crops such as pepper, a highly priced export agricultural crop. Since ERP is a non-renewable resource it is important to investigate methods for sustainable utilisation while improving the plant phosphorus $(\mathrm{P})$ nutrition. Hence this study was aimed at the sustainable utilization of ERP applied for pepper with the assistance of native Phosphate Solubilising Microorganisms (PSMs); Aspergillus sp. and Burkholderia sp. which have the potential of solubilizing ERP in a cheap and environmental friendly manner. A pot experiment for pepper was carried out with three inoculum levels i.e. Aspergillus sp. alone (F), Burkholderia sp. alone (B) and the combination of both species $(\mathrm{FB})$, and three fertilizer levels i.e. no $\mathrm{P}\left(\mathrm{P}_{0}\right)$, ERP at recommended level $\left(\mathrm{P}_{1}\right)$ and ERP at half recommended level $\left(\mathrm{P}_{1 / 2}\right)$. The treatments contained the combinations of inoculum and fertilizer level i.e. $\mathrm{FP}_{0}, \mathrm{FP}_{1}, \mathrm{FP}_{1 / 2}, \mathrm{BP}_{0}, \mathrm{BP}_{1}, \mathrm{BP}_{1 / 2}, \mathrm{FBP}_{0}, \mathrm{FBP}_{1}, \mathrm{FBP}_{1 / 2}$ and their counterparts with no inoculum, while $\mathrm{P}_{0}, \mathrm{P}_{1}$ (recommendation), $\mathrm{P}_{1 / 2}$ served as controls. All the treatments had Urea and Muriate of potash at the recommended level. The inocula, Aspergillus sp. and Burkholderia sp. were prepared in two different mass cultivation media i.e. rice straw supplemented with broken maize seeds at a ratio of 2:1 and rice straw supplemented with rice bran at a ratio of 1:1, respectively. Treatments were applied for 8 months old plants and completely randomized design was employed. Plant growth parameters: shoot dry weight and root dry weight and available soil $\mathrm{P}$, plant $\mathrm{P}$ uptake and soil microbial counts were quantitatively determined by destructive sampling of 4 replicates. Three destructive sampling sessions (DS) were done at 10 week time intervals; where the first destructive sampling was done after 10 weeks of inoculation. The results obtained were statistically analyzed using one way ANOVA at 5\% level of significance. Plant growth parameters were not significantly different. However, soil $P$ levels were significantly different $(p \leq 0.05)$. At $1^{\text {st }}$ DS the treatments having both fungal and bacterial inocula showed the highest soil $\mathrm{P}$ and plant $\mathrm{P}$ uptake. At $2^{\text {nd }}$ DS Aspergillus sp. was more persistent in soil than Burkholderia sp., hence the highest soil $\mathrm{P}$ and plant $\mathrm{P}$ uptake was observed in the treatments having only the fungal inoculum. Similar trend was observed at $3^{\text {rd }}$ DS as well. In each of these instances (with PSMs) the available soil $\mathrm{P}$ levels were significantly high compared to the recommendation $\left(\mathrm{P}_{1}\right)$. It was also observed that $\mathrm{P}_{1 / 2}$ along with PSMs showed similar performance when compared to $\mathrm{P}_{1}$ with PSMs. This concludes that the PSM inoculation facilitates the reduction of ERP application while improving the plant $\mathrm{P}$ nutrition which will ultimately lead towards the sustainable utilization of ERP.
\end{abstract}

Keywords: Eppawala Rock Phosphate (ERP), Phosphate Solubilising Microorganisms (PSMs), Pepper

Proceedings of the $22^{\text {nd }}$ International Forestry and Environment Symposium 2017 of the Department of Forestry and Environmental Science, University of Sri Jayewardenepura, Sri Lanka 